\title{
INTEGRATING THE BWM AND TOPSIS ALGORITHM TO EVALUATE THE OPTIMAL TOKEN EXCHANGES PLATFORM IN TAIWAN
}

\author{
Wei-Yuan WANG ${ }^{1}$, Yeh-Cheng YANG ${ }^{2}$, Chun-Yueh LIN² ${ }^{\star}$ \\ ${ }^{1}$ Department of Cultural and Creative Industries Management, National Taipei University \\ of Education, 134, Sec. 2, HePing E. Rd., Da-an Dist., Taipei City 106, Taiwan \\ ${ }^{2}$ Department of Public Finance and Tax Administration, National Taipei University of Business, \\ 321, Sec. 1, Jinan Rd., Zhongzheng Dist., Taipei City 100, Taiwan
}

Received 06 April 2021; accepted 05 October 2021; first published online 09 December 2021

\begin{abstract}
This research presents procedures for determining the optimal solution of token exchanges platform for investors in Taiwan via integrating the best-worst method (BWM) and the technique for ordering preference by similarity to the ideal solution (TOPSIS). Firstly, this research applies the modified Delphi method to develop the perspectives and factors via literature review and experts opinion. Secondly, the BWM is implemented to obtain weights of perspectives and factors on the linear programming concept. Thirdly, the TOPSIS model is used to rank the optimal solution of the token exchange for investors or corporations. Finally, the proposed model BWMTOPSIS-based procedures will list the optimal token exchanges platform on the three token exchange platforms to investors or corporations in Taiwan on the basis of their rankings in the architecture. The proposed combination framework is able to provide academic and commerce support to investors or corporations in implementing the token into their portfolio as a valuable objective guide to determine the optimal token exchange platform.
\end{abstract}

Keywords: bitcoin, token exchange platform, decision-making, Delphi method, Best-Worst Method (BWM), TOPSIS.

JEL Classification: C44, D81, G41.

\section{Introduction}

Recently, the blockchain-based cryptocurrency ecosystem has been attracting investors, regulators and speculators and so on. Chen and Bellavitis (2020) indicated that the blockchain technique can decrease the transaction costs, generate distributed trust, and empower decentralized platforms, potentially becoming a new foundation for decentralized business models. Therefore, they want to construct the new economic and business models for trade

*Corresponding author. E-mail: ljy898@gmail.com 
and investment. In financial fields, the blockchain-based technique was originally developed as the technology behind cryptocurrencies like Bitcoin. A vast, globally distributed ledger running on millions of devices, it is capable of recording anything of value (Tapscott \& Tapscott, 2017). Zhang et al. (2020) proposed that blockchain can safely store transactions such as digital crypto-currencies or data/information about debt, copyrights, equity, and digital assets. According to the CoinMarketCap website that indicates the rise of market in cryptocurrency market, with its total market capitals being \$366+ billions USD, as on August of 2020 (Coin Market Cap, 2020), the top 10 market capitals and relative criteria of cryptocurrencies are show in Table 1, many corporations are investing in cryptocurrencies to accept them as major trade instruments (Libra Association, 2019).

Due to its low transaction fees, merchants are able to lower their costs and improve their profitability (Chen \& Bellavitis, 2020). For investors, initial coin offering (ICO)s have emerged as an innovative funding mechanism for early-stage ventures, enabling startups and innovators to increase billions of dollars from global investors (Martino et al., 2019). There are various cryptocurrency exchanges which are accessible from all over the world. Separating the characteristics of the functioning of cryptocurrency invest platform (exchanges), they can be classified into three categories: (1) Decentralized exchanges (Ivaniuk, 2020; Xia et al., 2020; Tian et al., 2020; Bentov et al., 2019; Nabilou, 2019; Luo et al., 2019; Lee, 2019), (2) Centralized exchanges (Ivaniuk, 2020; Xia et al., 2020; Tian et al., 2020; Bentov et al., 2019; Luo et al., 2019) and (3) Margin lending exchanges (Xia et al., 2020; Ivaniuk, 2020).

The decentralized exchange platform is to offer direct person-to-person trading for individuals without the need to form a middleman that they are operated and maintained exclusively by software (Ivaniuk, 2020). Popular decentralized exchange platforms like Compound and Dharma have many differences. Compound is a floating interest rate and Dharma is a fixed interest rate; Dharma uses a time deposit structure while Compound uses a current deposit structure; Compound has compounding interest while Dharma does not; both suport different coins. According to the DeFi Market Cap website that shows the rise of market in decentralized tokens market, with its total market capitals being \$170+ billions USD (DeFi Market Cap, 2020). The top 10 market capitals in decentralized exchanges and relative criteria of tokens are show in Table 2. The advantages of decentralized exchanges platform for investors which include open code for mining cryptocurrency, no inflation, peer-to-peer cryptocurrency network, no boundaries, transparency and anonymity and so on and the disadvantages that have risk money laundry risk, terrorist and illegal activity financing and lack of a central issuer which represents that there is no legal formal unit to assurance the situation of any bankruptcy, and alike (Chen \& Bellavitis, 2020; Bunjaku et al., 2017; Vora, 2015). Past researches about the decentralized exchanges platform are concentrated on the analysis of potential problem and provide the solutions in decentralized exchanges platform (Chen \& Bellavitis, 2020; Ghosh et al., 2020), the application of blockchain technology (Singh et al., 2020; Pereira et al., 2019; Nizamuddin et al., 2019; Issaoui et al., 2019) and the business model analysis and application on decentralized exchanges platform (Kimani et al., 2020; Chen \& Bellavitis, 2020; Ahluwalia et al., 2020; Kumar et al., 2020; Lee, 2019) etc. 
Table 1. The top 10 on market capitals of cryptocurrencies in 2020 (source: Coin Market Cap, 2020)

\begin{tabular}{|c|l|c|c|c|c|}
\hline Rank & \multicolumn{1}{|c|}{ Name } & Market Cap & Price & Volume & Circulating Supply \\
\hline 1 & Bitcoin & $\$ 219,679,310,494$ & $11,889.05$ & $27,330,559,813$ & $18,477,450$ BTC \\
\hline 2 & Ethereum & $\$ 53,740,791,220$ & 477.99 & $19,321,812,596$ & $112,431,030$ ETH \\
\hline 3 & XRP & $\$ 13,468,921,708$ & 0.30 & $1,858,933,164$ & $44,994,863,318$ XRP \\
\hline 4 & Tether & $\$ 13,459,127,857$ & 1.00 & $50,455,204,000$ & $13,430,692,319$ USDT \\
\hline 5 & Chainlink & $\$ 5,630,358,881$ & 16.09 & $1,483,004,097$ & $350,000,000$ LINK \\
\hline 6 & Bitcoin Cash & $\$ 5,362,817,506$ & 289.78 & $1,825,084,351$ & $18,506,269$ BCH \\
\hline 7 & Litecoin & $\$ 4,108,015,224$ & 62.85 & $2,726,870,502$ & $65,364,257$ LTC \\
\hline 8 & Bitcoin SV & $\$ 3,731,654,286$ & 201.66 & $913,662,559$ & $18,504,883$ BSV \\
\hline 9 & Binance Coin & $\$ 3,658,101,413$ & 25.33 & $549,692,320$ & $144,406,560$ BNB \\
\hline 10 & Crypto.com Coin & $\$ 3,578,866,307$ & 0.18 & $82,320,135$ & $19,733,333,333$ CRO \\
\hline
\end{tabular}

Note: Unit - US dollars.

Table 2. The top 10 on market capitals of cryptocurrencies in 2020 (source: DeFi Market Cap, 2020)

\begin{tabular}{|c|c|c|c|c|}
\hline Rank & Name & Market Cap & Price & Circulating Supply \\
\hline \multirow{2}{*}{1} & \multirow{2}{*}{ UMA Voting Token v1 } & \multirow{2}{*}{$\$ 1,463,396,629$} & \multirow{2}{*}{$\$ 26.86$} & $54,475,686$ \\
\hline & & & & UMA \\
\hline \multirow{2}{*}{2} & \multirow{2}{*}{ Compound Dai } & \multirow{2}{*}{$\$ 1,016,510,374$} & \multirow{2}{*}{$\$ 0.02$} & $48,829,509,452$ \\
\hline & & & & cDAI \\
\hline \multirow{2}{*}{3} & \multirow{2}{*}{ Yearn.finance } & \multirow{2}{*}{$\$ 1,014,590,443$} & \multirow{2}{*}{$\$ 33,860.99$} & 29,963 \\
\hline & & & & YFI \\
\hline \multirow{2}{*}{4} & \multirow{2}{*}{ EthLend Token } & \multirow{2}{*}{$\$ 941,993,746$} & \multirow{2}{*}{$\$ 0.75$} & $1,256,361,932$ \\
\hline & & & & LEND \\
\hline \multirow{2}{*}{5} & \multirow{2}{*}{ Synthetix Network Token } & \multirow{2}{*}{$\$ 871,275,367$} & \multirow{2}{*}{$\$ 7.45$} & $116,890,573$ \\
\hline & & & & SNX \\
\hline \multirow{2}{*}{6} & \multirow{2}{*}{ Compound } & \multirow{2}{*}{$\$ 773,709,650$} & \multirow{2}{*}{$\$ 240.09$} & $3,222,544$ \\
\hline & & & & COMP \\
\hline \multirow{2}{*}{7} & \multirow{2}{*}{ Curve Y Pool } & \multirow{2}{*}{$\$ 686,504,604$} & \multirow{2}{*}{$\$ 1.05$} & $655,355,323$ \\
\hline & & & & yCrv \\
\hline \multirow{2}{*}{8} & \multirow{2}{*}{ Maker } & \multirow{2}{*}{$\$ 643,939,815$} & \multirow{2}{*}{$\$ 713.89$} & 902,021 \\
\hline & & & & MKR \\
\hline \multirow{2}{*}{9} & \multirow{2}{*}{ Ampleforth } & \multirow{2}{*}{$\$ 505,359,342$} & \multirow{2}{*}{$\$ 2.40$} & $210,465,977$ \\
\hline & & & & AMPL \\
\hline 10 & Comnound Fther & $\$ 472244935$ & $\$ 955$ & $49,443,723$ \\
\hline 10 & 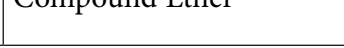 & $9472,244,303$ & (3) & cETH \\
\hline
\end{tabular}

Note: Unit - US dollars. 
With most cryptocurrencies' investors, the extreme important thing is that transacting in centralized exchange platform. The core basic of centralized exchanges are online platforms used to buy and sell cryptocurrencies. The centralized exchange platform includes intermediaries such as companies that act as a proxy in order to facilitate trading (Matkovskyy, 2019). This idea refers to the adopt of a middle sector or third-party unit for helping conduct the transactions. Buyers and sellers trust each other on this middle sector to handle their capitals. The trades from fiat-to-cryptocurrency and crypto-to-crypto can be applied in the centralized exchanges (Arslanian \& Fischer, 2019). Arslanian and Fischer (2019) indicated that users are able to deposit fiat assets in their E-wallet (e.g. USD, EUR, JPY) and convert these assets into the desired crypto-capital in fiat-to-cryptocurrency trade. By contrast, it does not connect the fiat token and only stimulates the swap of one crypto-capitals for another in cryptoto-crypto trade. The centralized cryptocurrency exchange such as NEXO and Celsius that also include some different among NEXO and Celsius, the NEXO is fixed interest rate and the Celsius is floating interest rate, frequency of interest payment in NEXO is per day and the Celsius is per week and so on. In the light of CoinGecko website that investigates the NEXO market capitals being 70+ millions USD (CoinGecko, 2020a) and the Celsius network market capitals being 174+ millions USD (CoinGecko, 2020b). Therefore, the centralized exchanges platform is an important vehicle for transacting in cryptocurrency. Shapiro (2018) proposed that both of the market participants and regulators have the advantages for implementing the centralized system. Market participants have not worry about the details of execution and risk of counterparty default, and they can obtain the advantages from liquidity provided by market makers in the crypto exchange field. Regulators who are able to lean on depositary for rules enforcement, accountability, and information reporting (Shapiro, 2018). However, the centralized exchanges also as some disadvantages. These disadvantages have expense (Shapiro, 2018), financial mismanagement, hacks by the centralized exchange providers that results in bankruptcy, operational mistakes through employees and unexpected account freezes (Luo et al., 2019). Moreover, the centralized exchanges finance cannot provide the high transparency, as centralized financial institutions have to secure their centralized ledgers by restricting access (Chen \& Bellavitis, 2020). Previous studies on the centralized exchanges platform are focused on the price discovery (Patel et al., 2020; Alexander et al., 2020), risk exposure analysis (Corbet et al., 2020; Brauneis \& Mestel, 2019), cryptocurrency volatility (Conrad et al., 2018; Walther et al., 2019; Bouri et al., 2019; Ma et al., 2020).

According to the literatures on hybrid exchanges platform which is a latest version of token exchange. Luo (2019) indicated that the EtherDelta platform is more like a hybrid design. The hybrid exchanges that combine the advantages of decentralized and centralized. Hybrid exchanges addresses the trade discovery issue via maintaining a centralized database of order management, while all trades are still applying the smart contracts to call procedures in exchange activity. conducted by calling procedures in the smart contracts. But, the hybrid exchanges does not fix the issue of high cost in terms of gas fee and transaction confirmation latency introduced by those frequent on-chain transactions. For frequent cryptocurrency traders, it's an extremely important thing which is more transactions in blockchain ecosystem imply more costs of gas fee and longer transaction confirmation latency. Moreover, the hybrid exchanges do not solve the potential transaction congestion problem caused by excessive simultaneous transactions (Luo, 2019). 
In recently, due to the rise of blockchain technology on token fields, more and more investors are paying attention to the token issues such as Bitcoin, Ethereum, Ripple, etc. That have three types of exchanges in the token platform which are centralized exchanges, decentralized exchanges, and hybrid exchanges. Some studies have identified the benefits and disadvantages on each platform based on the above explanations such as interest rate, costs issues, transparency issues, hack issues, risks and so on. Hence, the evaluation of token exchanges for investors is very complex and the determination of optimal exchanges and critical factors is also difficulty. Furthermore, many investors are lack of evaluation of the optimal token exchanges platform when they implement the crypto in their portfolio which involves a lot of risks on the investment. Past researches on topics of token fields are concentrated on the prediction of the price (Patel et al., 2020; Poongodi et al., 2020; Alexander et al., 2020), risk exposure analysis (Corbet et al., 2020; Brauneis \& Mestel, 2019), token volatility (Andrada-Félix et al., 2020; Conrad et al., 2018; Walther et al., 2019; Ma et al., 2020), risks problem (Xu et al., 2021; Enoksen et al., 2020; Liu et al., 2020). Although there are more literatures on the token field. But, they have not solve the problem of evaluation of the optimal token exchanges platform and critical factors for investors. Nowadays, there is no evidence that has built an integration framework to investors for assessing the optimal token platform and critical factors via decision science and investors in Taiwan are always lack of the techniques within the objective decision-making or determination of the optimal exchange in token and the risks of implementing an unsuitable crypto exchange are very high. Consequently, the aim of this work is to construct an integration evaluation framework combining the Delphi-BWM algorithm for obtaining the optimal token exchanges platform and critical factors.

The evaluation of optimal platform is optimal solution issue which can implement the multi-criteria decision-making (MCDM) method to construct a framework and to determine the optimal alternative (Lin, 2020; Hamdan \& Cheaitou, 2017; Lin, 2017). Literatures indicate that the optimization issues are able to solve by analytic hierarchy process (AHP) technique (Veisi et al., 2016; Roberti et al., 2017; Lee et al., 2018; Baidya et al., 2018; Kamaruzzaman et al., 2018; Ho \& Ma, 2018; Kilic \& Ucler, 2019; Achu et al., 2020). Even though the applications of AHP is very popular for each field. Nevertheless, the procedures of AHP are execution by pairwise comparison matrix. It would be a wrong decision on the determine process which include more complex comparison matrix when the evaluation framework comprise more indicators. Therefore, Rezaei $(2015,2016)$ proposed a new methodology is that BestWorst method (BWM), it can reduce the complex process of AHP method and obtain the optimal alternative and critical factor weights via multi-objective planning. Moreover, some advantages on BWM are that is a powerful method which can be used to find the weights of criteria (van de Kaa et al., 2017; Rezaei et al., 2018; Kheybari et al., 2019; Pamučar et al., 2020). The relative evidences are that Kheybari et al. (2019) applied the BWM to select the location of bioethanol facility. Omrani et al. (2020) integrated BWM and data envelopment analysis for evaluating the road safe. Malek and Desai (2019) implemented the BWM to measure the sustainable manufacturing barriers. However, although the BWM is able to reduce the complex of AHP methodology, the problem of ideal solutions in positive and negative are not analyzed by BWM model adequately in MCDM fields. The technique for 
order performance by similarity to ideal solution (TOPSIS) method that can rank the alternatives according to the closeness degrees of alternatives from idea solution (Hwang \& Yoon, 1981).Compared to other algorithm, the TOPSIS has been found to be more suitable when they have more factors and alternatives, especially for objective or quantitative data, as its ranking process is clearer and easier to implement (You et al., 2017; Nourmohamadi Shalke et al., 2018). Based on the above, this study integrates the TOPSIS algorithm into the BWM model then enhances its measuring quality and efficiency. With exception of the reviews and surveying experts in the financial area such as investors and financial scholars, this work applies the modified Delphi method, BWM, and TOPSIS to develop a BWM-TOPSIS based evaluation framework which can assess the optimal token exchanges platform and critical factors in Taiwan for investors or corporations.

Consequently, this work integration of the modified Delphi model, BWM with TOPSIS algorithm for measuring the synthesis weights of the perspectives and factors of the token exchanges platform for investors or corporations, the weight of each factor was determined by BWM model, and then the optimal token exchange platform was obtained via TOPSIS. In academic, the combination of BWM-TOPSIS model which can provide investors or corporations for assessing the optimal token exchanges platform to investors in Taiwan cryptotoken fields. In commercial, the proposed framework can provide investors or managers with a useful instrument to measure the optimal token exchanges platform for investors or corporations in Taiwan.

This paper is established into 3 additional parts. We describe the combination algorithms of the BWMTOPSIS-based framework in Section 1. An empirical study and the results appear in Section 2. Finally, last Section sets our concluding remarks.

\section{Delphi Best-Worst Method and TOPSIS algorithm}

To obtain the experts' opinions and point out the determinants of the model by the modified Delphi method and then calculation of the weighted factors by Best-Worst Method (BWM). The Delphi BWM and TOPSIS procedures are follows.

\subsection{Modified Delphi method}

To collect and analyze the opinions of anonymous experts by writing, discussion and feedback on decision-making problems and then based on the experts' knowledge, skills, expertise, and opinions to achieve a mutual consensus which is the core concepts of Delphi method (Sung, 2001). Wu et al. (2007) indicated that the procedures of Delphi method are as shown below (Wu et al., 2007):

I. Selecting the anonymous specialists.

II. Collecting and conducting the specialists' opinions of the survey in first round.

III. Collecting and conducting the specialists' questionnaire survey in second round.

IV. Collecting and conducting the specialists' questionnaire survey in third round.

V. Integration of specialists suggestions and achieve a consensus.

Phase III and IV are regularly duplicated to a consensus is achieved on a decision-making problem (Sung, 2001). Phase II is simplified in order to replace the conventionally employed 
open style investigation; it is commonly referred to as the modified Delphi method if the phase II is done (Sung, 2001). This work constructs a quality combination model in assessing the optimal token exchanges platform and critical factors, then a case study of 3 categories of token exchanges platform in Taiwan based on the modified Delphi model and obtain the consensus by interviews with nameless experts and investors. Hasson and Keeney (2011) proposed that the number of specialists in the expert decision issue should be between five and nine.

\subsection{BWM for obtaining the relative weights}

The BWM algorithm include 5 steps to evaluate the weights on decision issues. This algorithm was developed by Rezaei $(2015,2016)$. The BWM has been successfully implemented to other research problems such as location selection (Kheybari et al., 2019), measuring the sustainable manufacturing barriers (Malek \& Desai, 2019) and logistics performance index evaluation (Rezaei et al., 2018). Here we present the 5 steps of the BWM processes (Rezaei, 2015, 2016):

Step 1. Determination of a set of decision criteria.

In the first step, the decision criteria $\left\{C_{1}, C_{2}, C_{3}, \ldots, C_{n}\right\}$ need to be identified in order to arrive at a decision and the factors are considered that should be implemented for evaluating the goal. In this work, the modified Delphi method is applied to collect decision criteria for assessing the optimal token exchanges platform to investors in Taiwan which may be presented at different levels.

Step 2. Select the best criteria and worst criteria.

The respondents must determine the best criterion (the most important criterion) and worst criterion (the last important criterion). Here only consider the best and worst criterion not the values of the criteria and alternatives.

Step 3. Determination of the preference and best-to-others (BO) of the best criterion over all the other criteria, using a number from 1 to 9.

In this step, respondents determine their preference based on a number from 9 to 1 , where 9 means that the best criterion is more important compared to the other criterion, while 1 represents equal importance. The result is a $\mathrm{BO}$ vector as follows.

$$
A_{b}=\left(a_{b 1}, a_{b 2}, \ldots, a_{b n}\right) \text {, }
$$

where $a_{b j}$ indicates the preference of $b$ over $j$ and $a_{b j}=1$.

Step 4. Determination of the all preference and others-to-worst (OW) of all the criteria over the worst, using a number from 1 to 9 .

The respondents applying a number between 1 to 9 for evaluating their preference of all the other factors over the factor choose as being the least important, where equal importance is 1 and the factor in question is more important than the least important factor is 9 . The result is an $\mathrm{OW}$ vector as follows.

$$
A_{w}=\left(a_{1 w}, a_{2 w}, \ldots, a_{n w}\right)^{T},
$$

where $a_{j w}$ indicates the preference of $j$ over $w$ and $a_{w w}=1$. 
Step 5. Evaluate the optimal weights.

In this step, the optimal weights $\left(w_{1}^{*}, w_{2}^{*}, w_{3}^{*}, \ldots, w_{n}^{*}\right)$ are determined. The series of optimal synthesis weights for the linear framework is the one where the maximum absolute difference for the following set $\left(\left|\frac{W_{b}}{W_{j}}-a_{b j}\right|,\left|\frac{W_{j}}{W_{w}}-a_{j w}\right|\right)$ is minimized. The sum of the weights has to equal to 1 and none of the weights is able to negative, leading to the subjects to evaluate the optimal solution.

Subject to

$$
\min \max _{j}\left\{\left|\frac{W_{b}}{W_{j}}-a_{b j}\right|,\left|\frac{W_{b}}{W_{j}}-a_{b j}\right|\right\} .
$$

$\sum_{j} w_{j}=1$

$w_{j} \geq 0$, for all $j$.

The problem is able to solve via transferring it to a linear programming problem (4).

$$
\min \zeta^{L} \text {. }
$$

Subject to

$$
\begin{aligned}
& \left|w_{b}-a_{b j} w_{j}\right| \leq \zeta^{L}, \text { for all } j, \\
& \left|w_{j}-a_{j w} w_{w}\right| \leq \zeta^{L}, \text { for all } j, \\
& \sum_{j} w_{j}=1, \\
& w_{j} \geq 0, \text { for all } j,
\end{aligned}
$$

By solving the linear programming problem (4), we can acquire the optimal weight and $\zeta^{L}$. $\zeta^{L}$ is the consistency rate of the comparison system. The consistency rate value close to 0 show a high level of consistency of the pairwise comparisons by the respondents.

To obtain the consistency of the comparisons, we apply the following formula:

$$
\text { Consistency ratio }=\frac{\zeta^{L}}{\text { Consistency index }} .
$$

The consistency index can be retrieved from Table 3 .

The thresholds of consistency ratio are as show in Table 4. For example, if we have a problem with 4 criteria and the maximum value in the pairwise comparison system is 8 , then the threshold is 0.3409 , which means that values of consistency ratio below 0.3409 are acceptable for such problem.

Table 3. The consistency index (CI) (source: Rezaei, 2015)

\begin{tabular}{|l|c|c|c|c|c|c|c|c|c|}
\hline$a_{b w}$ & 1 & 2 & 3 & 4 & 5 & 6 & 7 & 8 & 9 \\
\hline$C I(\max \zeta)$ & 0.00 & 0.44 & 1.00 & 1.63 & 2.30 & 3.00 & 3.73 & 4.47 & 5.23 \\
\hline
\end{tabular}


Table 4. The thresholds of consistency ratio (source: Liang et al., 2020)

\begin{tabular}{|c|c|c|c|c|c|c|c|}
\hline$a b_{w}$ Criteria & 3 & 4 & 5 & 6 & 7 & 8 & 9 \\
\hline 3 & 0.2087 & 0.2087 & 0.2087 & 0.2087 & 0.2087 & 0.2087 & 0.2087 \\
\hline 4 & 0.1581 & 0.2352 & 0.2738 & 0.2928 & 0.3102 & 0.3154 & 0.3273 \\
\hline 5 & 0.2111 & 0.2848 & 0.3019 & 0.3309 & 0.3479 & 0.3611 & 0.3741 \\
\hline 6 & 0.2164 & 0.2922 & 0.3565 & 0.3924 & 0.4061 & 0.4168 & 0.4225 \\
\hline 7 & 0.2090 & 0.3313 & 0.3734 & 0.3931 & 0.4035 & 0.4108 & 0.4298 \\
\hline 8 & 0.2267 & 0.3409 & 0.4029 & 0.4230 & 0.4379 & 0.4543 & 0.4599 \\
\hline 9 & 0.2122 & 0.3653 & 0.4055 & 0.4225 & 0.4445 & 0.4587 & 0.4747 \\
\hline
\end{tabular}

\subsection{TOPSIS model for ranking the crypto exchange platforms}

TOPSIS was first proposed by Hwang and Yoon (1981). Defining the ideal solutions on positive and negative are the core principle in TOPSIS method. The aim of the ideal solution is to maximizes the benefit perspective and factor and minimizes the cost perspective and factor, whereas the negative ideal solution maximizes the cost perspective and factor and minimizes the benefit and factor. If the solution is closest to the ideal solution and farthest from the negative ideal solution which is the optimal alternative. The sequence of alternatives in TOPSIS is based on the "relative similarity to the ideal solution", which avoids the situation of having the same similarity to both the ideal and negative ideal solutions. The evaluation process using this algorithm is described as follows.

Step 1. Establish a decision (D) matrix for the alternatives

$$
D=\begin{gathered}
A_{1} \\
A_{2} \\
\vdots \\
A_{i} \\
\vdots \\
A_{m}
\end{gathered}\left[\begin{array}{cccccc}
X_{11} & X_{12} & \cdots & \cdots & X_{1 j} & X_{1 n} \\
X_{21} & X_{22} & \cdots & \cdots & X_{2 j} & X_{2 n} \\
\vdots & \vdots & \cdots & \vdots & \vdots & \vdots \\
X_{i 1} & X_{i 2} & \vdots & \vdots & X_{i j} & X_{i n} \\
\vdots & \vdots & \cdots & \vdots & \vdots & \vdots \\
X_{m 1} & X_{m 2} & \cdots & \cdots & X_{m j} & X_{m n}
\end{array}\right],
$$

where $A_{i}$ represents the decision units, $i=1, \ldots, m ; X_{j}$ indicates elements and factors related to decision units performance, $j=1, \ldots, n$; and $X_{i j}$ is a crisp value representing the score of each decision unit $A_{i}$ regarding each factor $X_{j}$.

Step 2. Normalizing the D matrix

Evaluate the normalization results of $D$ matrix $R\left(=\left[r_{i j}\right]\right)$. The Eq. (7) was the normalize formula that $r_{i j}$ is the normalized value.

$$
r_{i j}=\frac{X_{i j}}{\sqrt{\sum_{j=1}^{n} X_{i j}^{2}}}, j=1, \ldots, n ; i=1, \ldots, m .
$$

Here, $X_{i j}$ is the scores of factor $i$ in terms of criterion $j$. 
Step 3. Create the weighted normalized matrix

To create the weighted normalized matrix, a series of weights $w=\left(w_{1}, w_{2}, \ldots, w_{n}\right), \sum_{j=1}^{n}$ $w_{j}=1$, from the BWM algorithm. The matrix is able to compute via multiplying each column of the $R$ with its relative weight $w_{j}$. Accordingly, the Eq. (8) was the weighted normalized formula that $V$ is the weighted decision matrix.

$$
V=\left[\begin{array}{cccccc}
V_{11} & V_{12} & \cdots & V_{1 j} & \cdots & V_{1 n} \\
\vdots & \vdots & & \vdots & & \vdots \\
V_{i 1} & V_{i 2} & \cdots & V_{i j} & \cdots & V_{i n} \\
\vdots & \vdots & & \vdots & & \vdots \\
V_{m 1} & V_{m 2} & \cdots & V_{m j} & \cdots & V_{m n}
\end{array}\right]=\left[\begin{array}{cccccc}
w_{1} r_{11} & w_{2} r_{12} & \cdots & w_{j} r_{i j} & \cdots & w_{n} r_{1 n} \\
\vdots & \vdots & & \vdots & & \vdots \\
w_{1} r_{i 1} & w_{2} r_{i 2} & \cdots & w_{j} r_{i j} & \cdots & w_{n} r_{i n} \\
\vdots & \vdots & & \vdots & & \vdots \\
w_{1} r_{m 1} & w_{2} r_{m 2} & \cdots & w_{j} r_{m j} & \cdots & w_{n} r_{m n}
\end{array}\right] .
$$

Step 4. Create the weighted normalized matrix

The ideal solution is evaluated by the following equations:

where

$$
\begin{aligned}
& A^{*}=\left\{\left(\max V_{i j} \mid j \in J\right),\left(\min V_{i j} \mid j \in J^{\prime}\right), i=1,2, \ldots, m\right\}, \\
& A^{-}=\left\{\left(\min V_{i j} \mid j \in J\right),\left(\max V_{i j} \mid j \in J^{\prime}\right), i=1,2, \ldots, m\right\},
\end{aligned}
$$

$j=\{j=1,2, \ldots, n \mid j$ belongs to benefit criteria $\}$,

$j^{\prime}=\{j=1,2, \ldots, n \mid j$ belongs to cost criteria $\}$.

Step 5. Calculate the distance between the ideal solution and negative ideal solution for each alternative

Applying the Eq. (11) and Eq. (12) to obtain the distance of the ideal and negative ideal solutions for each alternative.

$$
\begin{aligned}
& S_{i}^{*}=\sqrt{\sum_{j=1}^{n}\left(V_{i j}-V_{j}^{*}\right)^{2}} \quad i=1,2, \ldots, m ; \\
& S_{i}^{-}=\sqrt{\sum_{j=1}^{n}\left(V_{i j}-V_{j}^{-}\right)^{2}} \quad i=1,2, \ldots, m .
\end{aligned}
$$

Step 6. Calculate the relative closeness to the ideal solution of each alternative

The relative closeness to the ideal solution of each alternative is calculated as follows:

$$
C_{i}^{*}=\frac{S_{i}^{-}}{S_{i}^{*}+S_{i}^{-}} i=1,2, \ldots, m,
$$

where $0 \leq C_{i}^{*} \leq 1$ that is, an alternative $i$ is closer to $A^{*}$ as $C_{i}^{*}$ approaches 1 .

Step 7. Rank the preference order

A set of the token exchange platforms can be preference ranked according to the descending order of $C_{i}^{*}$. 


\section{Empirical study}

This work established indicators to assess the optimal token exchanges platform and critical factors in Taiwan for investors, and then determines an associated weight to each factor based on the BWMTOPSIS framework for ranking the optimal token exchanges platform and the research hierarchy is show in Figure 1. The integration framework is established by the modify Delphi model for determining the optimal token exchanges platform and critical factors in Taiwan via using BWM algorithm. This procedure is to evaluate the optimal token exchanges platform and critical factors in Taiwan that comprises the following steps (see Figure 2).

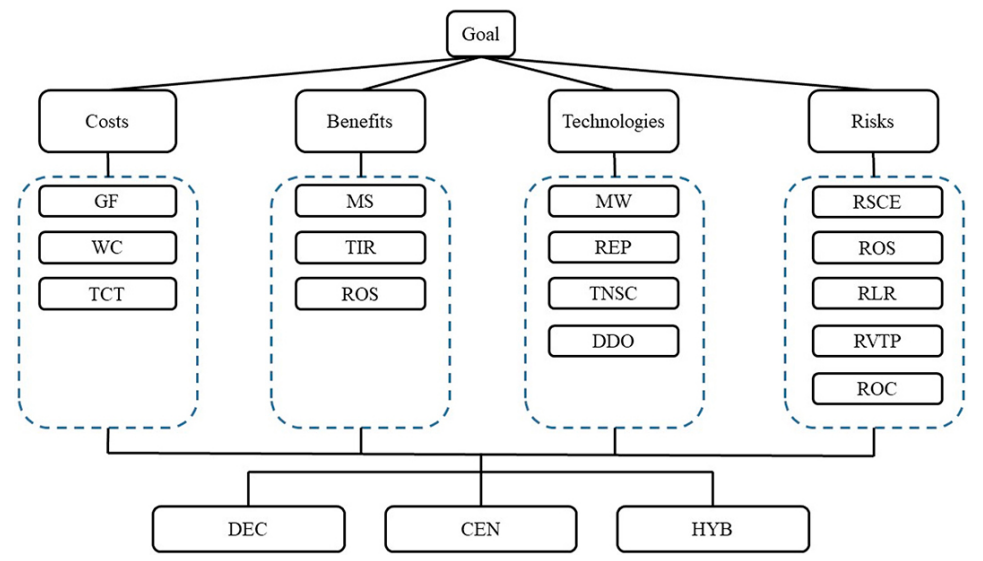

Figure 1. The research framework to evaluate the optimal token exchanges platform and critical factors in Taiwan

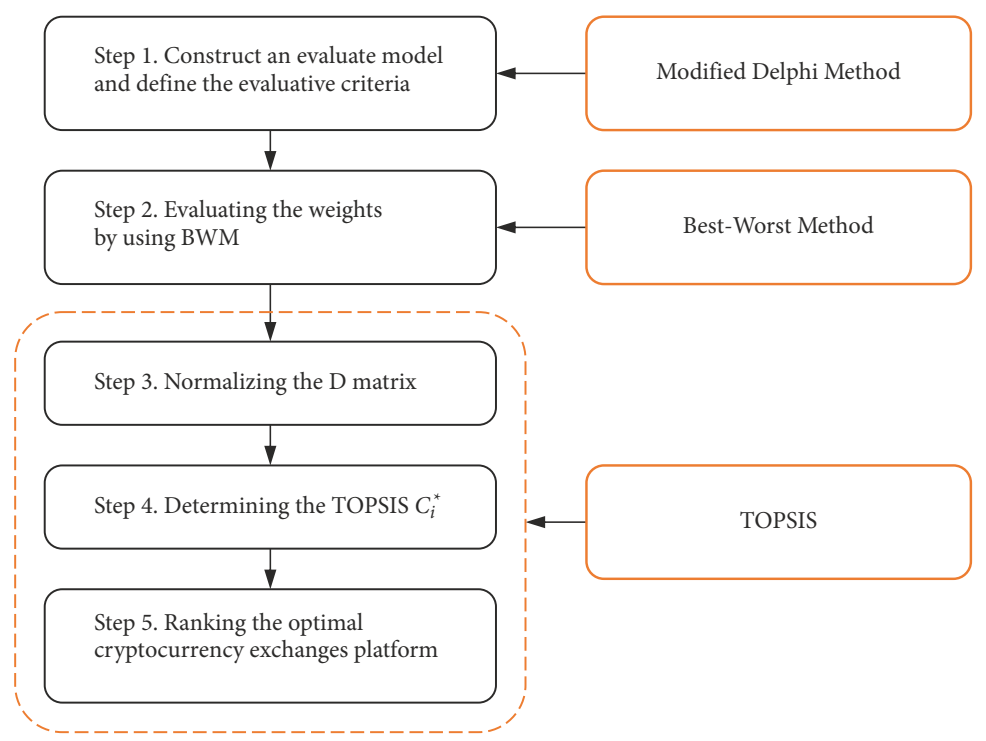

Figure 2. The research processes of the combination model 
Step 1. Construct an evaluate model and define the evaluative factors

In the light of the review, it have to achieve the consensus among experts for developing the research model (Ali-Yrkko et al., 2011; Linden et al., 2009). The final target of determining the optimal token exchanges platform and critical factors in Taiwan can be achieved, followed by 4 evaluation perspectives, 15 factors and final token exchange alternatives (Figure 1) and the reference as shows in Table 5.

The evaluation perspectives and factors utilized to evaluate the optimal token exchanges platform in Taiwan are defined as follows:

1. Costs perspective:

1.1. Gas fees: the fees of maker and taker in the token exchange platform.

1.2. Withdraw costs: the fees of withdraw from the token exchange platform.

1.3. Time costs of transaction: the speed and efficiency of deposit/withdrawal in the token exchange platform.

2. Benefits perspective:

2.1. Mechanism of savings: the different mechanism of savings in token exchange platform such as current deposit and timed deposit.

2.2. Type of interest rate: the types and different level of interest rate in token exchange platform such as fixed rate and floating rate.

2.3. Returns of stablecoin: the internal rate of return of pegging token in token exchange platform.

3. Technologies perspective:

3.1. Mechanism of withdrawal: the different mechanism of withdrawal in token exchange platform such as slowly, immediately and immediately by trader repayment.

3.2. Regulated exchanges and providers: the different type of regulated exchange and provider in token exchange platform such as smart contract, Bitgo and Gemini.

3.3. The number of support coins: that have different scale of tokens in each token exchange platform.

3.4. Degree of difficulty in operation: the user experience and user interface in different platform such as operation speed and complexity of the transaction process, etc.

4. Risks perspective:

4.1. Risk of smart contract execution: the risks of security in smart contract such as the coding errors and hacks.

4.2. Risk of operational security: the admin keys allow a predefined group of individuals to upgrade the contracts and to perform emergency events. If the keyholders do not create or store their keys in a secure way, malicious third parties could get their hands on the keys.

4.3. Risk of legal and regulatory: the uncertainty of regulations in token fields.

4.4. Risk of volatility in token price: the degree of volatility of tokens price in platform.

4.5. Risk of collapse: the risk of collapse in token exchanges platform which the reasons have low transaction volume, liquidity and exit scam. 
Table 5. The perspectives, factors and platforms

\begin{tabular}{|c|c|c|c|c|c|}
\hline & Perspectives & Factors & Literatures & Platforms & Literatures \\
\hline \multirow{15}{*}{ Goal } & \multirow{3}{*}{$\begin{array}{l}\text { Costs } \\
\text { perspective }\end{array}$} & Gas Fees & $\begin{array}{l}\text { (Chen \& Bellavitis, } \\
\text { 2020; Easley et al., } \\
\text { 2019; Rehman et al., } \\
\text { 2019) }\end{array}$ & $\begin{array}{l}\text { Decentralized } \\
\text { Exchanges } \\
\text { Platform }\end{array}$ & $\begin{array}{l}\text { (Ivaniuk, 2020; } \\
\text { Xia et al., 2020; } \\
\text { Tian et al., 2020; } \\
\text { Bentov et al., 2019; } \\
\text { Nabilou, 2019; } \\
\text { Luo et al., 2019; } \\
\text { Lee, 2019) }\end{array}$ \\
\hline & & Withdraw Costs & (Chuen et al., 2018) & $\begin{array}{l}\text { Centralized } \\
\text { Exchanges } \\
\text { Platform }\end{array}$ & $\begin{array}{l}\text { (Ivaniuk, 2020; } \\
\text { Xia et al., 2020; } \\
\text { Tian et al., 2020; } \\
\text { Bentov et al., 2019; } \\
\text { Luo et al., 2019) }\end{array}$ \\
\hline & & $\begin{array}{l}\text { Time Costs of } \\
\text { Transaction }\end{array}$ & $\begin{array}{l}\text { (Rehman et al., } \\
\text { 2019; Ricci et al., } \\
\text { 2018) }\end{array}$ & $\begin{array}{l}\text { Hybrid } \\
\text { Exchanges } \\
\text { Platform }\end{array}$ & $\begin{array}{l}\text { (Xia et al., 2020; } \\
\text { Ivaniuk, 2020; } \\
\text { Luo et al., 2019) }\end{array}$ \\
\hline & \multirow{3}{*}{$\begin{array}{l}\text { Benefits } \\
\text { perspective }\end{array}$} & $\begin{array}{l}\text { Mechanism of } \\
\text { Savings }\end{array}$ & & & \\
\hline & & $\begin{array}{l}\text { Type of Interest } \\
\text { Rate }\end{array}$ & & & \\
\hline & & $\begin{array}{l}\text { Returns of } \\
\text { Stablecoin }\end{array}$ & (Moin et al., 2019) & & \\
\hline & \multirow{4}{*}{$\begin{array}{l}\text { Technologies } \\
\text { perspective }\end{array}$} & $\begin{array}{l}\text { Mechanism of } \\
\text { Withdrawal }\end{array}$ & & & \\
\hline & & $\begin{array}{l}\text { Regulated } \\
\text { Exchanges and } \\
\text { Providers }\end{array}$ & $\begin{array}{l}\text { (Silfversten et al., } \\
\text { 2020) }\end{array}$ & & \\
\hline & & $\begin{array}{l}\text { The Number of } \\
\text { Support Coins }\end{array}$ & (Moin et al., 2019) & & \\
\hline & & $\begin{array}{l}\text { Degree of } \\
\text { Difficulty in } \\
\text { Operation }\end{array}$ & $\begin{array}{l}\text { (Rehman et al., } \\
\text { 2019; Peters et al., } \\
\text { 2016) }\end{array}$ & & \\
\hline & \multirow{5}{*}{$\begin{array}{l}\text { Risks } \\
\text { perspective }\end{array}$} & $\begin{array}{l}\text { Risk of Smart } \\
\text { Contract } \\
\text { Execution }\end{array}$ & (Schär, 2020) & & \\
\hline & & $\begin{array}{l}\text { Risk of } \\
\text { Operational } \\
\text { Security }\end{array}$ & $\begin{array}{l}\text { (Schär, 2020; Aziz, } \\
\text { 2019) }\end{array}$ & & \\
\hline & & $\begin{array}{l}\text { Risk of Legal and } \\
\text { Regulatory }\end{array}$ & $\begin{array}{l}\text { (Söylemez, 2019; } \\
\text { Rehman et al., } \\
\text { 2019) }\end{array}$ & & \\
\hline & & $\begin{array}{l}\text { Risk of Volatility } \\
\text { in Token Price }\end{array}$ & $\begin{array}{l}\text { (Aziz, 2019; } \\
\text { Rehman et al., } \\
\text { 2019) }\end{array}$ & & \\
\hline & & Risk of Collapse & $\begin{array}{l}\text { (Rehman et al., } \\
\text { 2019) }\end{array}$ & & \\
\hline
\end{tabular}


5. Token exchanges platforms:

5.1. Decentralized exchanges platform: this platform is to offer direct person-to-person trading for individuals without the need to form a middleman that they are operated and maintained exclusively by smart contract that can reduce the risks of exit scam. But, the fundamentals are an uncertainty problem.

5.2. Centralized exchanges platform: this platform refers to the use of a middle sector or third-party institute to assist conduct transactions. Buyers and sellers trust each other on this middle sector to handle their capitals. The transaction volume and liquidity are stable. But, the risks of safety and scam issues are higher for investors.

5.3. Hybrid exchanges platform: The hybrid exchanges that combines the advantages of decentralized and centralized. But, the hybrid exchanges does not fix the issue of high cost in terms of gas fees and transaction confirmation latency introduced by those frequent on-chain transactions.

Step 2. Evaluating the weights by using BWM

This step is to confirm the best criterion and worst criterion by 7 experts then obtain the weights via BWM model. These experts include 3 scholars in the financial sector; 2 investors of crypto in the commercial field, and 2 experts in government.

Firstly, the best criterion and worst criterion could be different based on the perception of experts. Based on the opinion of each expert, the best and worst criteria are show in Table 6 . Secondly, determination of the preference and best-to-others of the best criterion over all the other criteria, using a number from 1 to 9. The results are as shown in Table 7. Thirdly, Determination of the all preference and others-to-worst (OW) of all the criteria over the worst, using a number from 1 to 9 (see Table 8). Finally, calculating the weights by the linear programing concept. The results are as shown in Table 9 and Table 10, and the Figure 3 shows that the weights of each factor for three platforms by means of BWM algorithm.

Table 6. The best and worst criteria in perspectives and factors

\begin{tabular}{|c|l|l|c|c|c|c|c|c|c|c|}
\hline \multirow{3}{*}{ Experts } & \multirow{2}{*}{ Perspectives } & \multicolumn{9}{|c|}{ Factors } \\
\cline { 3 - 12 } & \multicolumn{2}{|c|}{$\begin{array}{c}\text { Costs } \\
\text { perspectives }\end{array}$} & \multicolumn{2}{c|}{$\begin{array}{c}\text { Benefits } \\
\text { perspectives }\end{array}$} & \multicolumn{2}{|c|}{$\begin{array}{c}\text { Technologies } \\
\text { perspectives }\end{array}$} & \multicolumn{2}{c|}{$\begin{array}{c}\text { Risks } \\
\text { perspectives }\end{array}$} \\
\cline { 2 - 12 } & Best & Worst & Best & Worst & Best & Worst & Best & Worst & Best & Worst \\
\hline 1 & Benefits & Technologies & TCT & GF & TIR & ROS & TNSC & REP & ROC & RLR \\
\hline 2 & Risks & Technologies & TCT & GF & TIR & ROS & DDO & TNSC & ROC & RLR \\
\hline 3 & Risks & Costs & TCT & WC & TIR & ROS & REP & MW & ROC & RSCE \\
\hline 4 & Benefits & Technologies & GF & TCT & ROS & MS & TNSC & MW & RLR & ROC \\
\hline 5 & Costs & Technologies & GF & WC & ROS & MS & MW & REP & ROS & RVTP \\
\hline 6 & Benefits & Costs & GF & WC & TIR & MS & MW & REP & ROC & RLR \\
\hline 7 & Benefits & Technologies & GF & WC & TIR & MS & DDO & REP & ROC & RLR \\
\hline
\end{tabular}

Note: Time costs transaction (TCT), Gas fee (GF), Withdraw costs (WC), Type of interest rate (TIR), Returns of stablecoin (ROS), Mechanism of savings (MS), The number of support coins (TNSC), Degree of difficulty in operation (DDO), Regulated exchanges and providers (REP), Mechanism of withdrawal (MW), Risk of collapse (ROC), Risk of legal and regulatory (RLR), Risk of operational security (ROS), Risk of smart contract execution (RSCE), Risk of volatility in token price (RVTP). 
Table 7. The preferences of perspectives in $\mathrm{BO}$

\begin{tabular}{|c|c|c|c|c|}
\hline \multirow{2}{*}{ Experts } & \multicolumn{5}{|c|}{ Perspectives } \\
\cline { 2 - 5 } & Costs & Benefits & Technologies & Risks \\
\hline 1 & 4 & 1 & 8 & 3 \\
\hline 2 & 3 & 5 & 9 & 1 \\
\hline 3 & 6 & 5 & 5 & 1 \\
\hline 4 & 4 & 1 & 8 & 3 \\
\hline 5 & 1 & 5 & 9 & 5 \\
\hline 6 & 9 & 1 & 5 & 4 \\
\hline 7 & 3 & 1 & 7 & \\
\hline
\end{tabular}

Table 8. The preferences of perspectives in OW

\begin{tabular}{|c|l|l|l|l|l|l|l|l|}
\hline \multicolumn{2}{|c|}{ Experts } & 1 & 2 & 3 & 4 & 5 & 6 & 7 \\
\hline \multirow{4}{*}{ Perspectives } & Costs & 4 & 6 & 1 & 5 & 9 & 1 & 7 \\
\cline { 2 - 9 } & Benefits & 8 & 3 & 9 & 8 & 3 & 9 & 8 \\
\cline { 2 - 9 } & Technologies & 1 & 1 & 5 & 1 & 1 & 5 & 1 \\
\cline { 2 - 9 } & Risks & 3 & 9 & 6 & 3 & 5 & 5 & 5 \\
\hline
\end{tabular}

Table 9. The weights and consistency ratio in perspectives

\begin{tabular}{|c|c|c|c|c|c|c|}
\hline \multirow{2}{*}{ Experts } & \multicolumn{6}{|c|}{ Perspectives } \\
\cline { 2 - 7 } & Costs & Benefits & Technologies & Risks & C.R. & C.R. Threshold \\
\hline 1 & 0.161 & 0.564 & 0.060 & 0.215 & 0.081 & 0.341 \\
\hline 2 & 0.227 & 0.136 & 0.054 & 0.583 & 0.097 & 0.365 \\
\hline 3 & 0.051 & 0.176 & 0.176 & 0.596 & 0.287 & 0.365 \\
\hline 4 & 0.183 & 0.610 & 0.061 & 0.146 & 0.122 & 0.341 \\
\hline 5 & 0.590 & 0.132 & 0.058 & 0.220 & 0.069 & 0.365 \\
\hline 6 & 0.056 & 0.637 & 0.153 & 0.153 & 0.129 & 0.365 \\
\hline 7 & 0.231 & 0.540 & 0.055 & 0.174 & 0.154 & 0.341 \\
\hline Avg. & 0.214 & 0.399 & 0.088 & 0.298 & 0.134 & 0.341 \\
\hline
\end{tabular}


Table 10. The final weights and rank in the optimal token exchange platform, perspectives and factors

\begin{tabular}{|c|c|c|c|c|c|c|c|c|c|}
\hline & $\begin{array}{l}\text { Perspec- } \\
\text { tives }\end{array}$ & Weights & Factors & $\begin{array}{c}\text { Local } \\
\text { weights }\end{array}$ & $\begin{array}{l}\text { Global } \\
\text { weights }\end{array}$ & Rank & $\begin{array}{l}\text { Decen- } \\
\text { tralized }\end{array}$ & $\begin{array}{c}\text { Central- } \\
\text { ized }\end{array}$ & Hybrid \\
\hline \multirow{15}{*}{ Goal } & \multirow{3}{*}{$\begin{array}{l}\text { Costs } \\
\text { perspec- } \\
\text { tive }\end{array}$} & \multirow{3}{*}{0.214} & Gas fees & 0.462 & 0.099 & 4 & 0.462 & 0.172 & 0.366 \\
\hline & & & $\begin{array}{l}\text { Withdraw } \\
\text { costs }\end{array}$ & 0.171 & 0.037 & 11 & 0.561 & 0.155 & 0.285 \\
\hline & & & $\begin{array}{l}\text { Time } \\
\text { costs of } \\
\text { transaction }\end{array}$ & 0.367 & 0.079 & 5 & 0.374 & 0.455 & 0.170 \\
\hline & \multirow{3}{*}{$\begin{array}{l}\text { Benefits } \\
\text { perspec- } \\
\text { tive }\end{array}$} & \multirow{3}{*}{0.399} & $\begin{array}{l}\text { Mechanism } \\
\text { of savings }\end{array}$ & 0.127 & 0.050 & 7 & 0.414 & 0.352 & 0.234 \\
\hline & & & Interest rate & 0.587 & 0.234 & 1 & 0.493 & 0.218 & 0.289 \\
\hline & & & $\begin{array}{l}\text { Returns of } \\
\text { stablecoin }\end{array}$ & 0.286 & 0.114 & 2 & 0.365 & 0.233 & 0.402 \\
\hline & \multirow{4}{*}{$\begin{array}{l}\text { Tech- } \\
\text { nologies } \\
\text { perspec- } \\
\text { tive }\end{array}$} & \multirow{4}{*}{0.088} & $\begin{array}{l}\text { Mechanism } \\
\text { of } \\
\text { withdrawal }\end{array}$ & 0.272 & 0.024 & 13 & 0.529 & 0.270 & 0.200 \\
\hline & & & $\begin{array}{l}\text { Regulated } \\
\text { exchanges } \\
\text { and } \\
\text { providers }\end{array}$ & 0.151 & 0.013 & 15 & 0.252 & 0.502 & 0.246 \\
\hline & & & $\begin{array}{l}\text { The } \\
\text { number } \\
\text { of support } \\
\text { coins }\end{array}$ & 0.256 & 0.023 & 14 & 0.383 & 0.202 & 0.415 \\
\hline & & & $\begin{array}{l}\text { Degree of } \\
\text { difficulty in } \\
\text { operation }\end{array}$ & 0.321 & 0.028 & 12 & 0.384 & 0.354 & 0.262 \\
\hline & \multirow{5}{*}{$\begin{array}{l}\text { Risks } \\
\text { perspec- } \\
\text { tive }\end{array}$} & \multirow{5}{*}{0.298} & $\begin{array}{l}\text { Risk of } \\
\text { smart } \\
\text { contract } \\
\text { execution }\end{array}$ & 0.166 & 0.049 & 8 & 0.225 & 0.569 & 0.206 \\
\hline & & & $\begin{array}{l}\text { Risk of } \\
\text { operation } \\
\text { security }\end{array}$ & 0.202 & 0.060 & 6 & 0.583 & 0.203 & 0.214 \\
\hline & & & $\begin{array}{l}\text { Risk of } \\
\text { legal and } \\
\text { regulatory }\end{array}$ & 0.149 & 0.044 & 9 & 0.321 & 0.443 & 0.236 \\
\hline & & & $\begin{array}{l}\text { Risk of } \\
\text { volatility in } \\
\text { token price }\end{array}$ & 0.135 & 0.040 & 10 & 0.470 & 0.235 & 0.295 \\
\hline & & & $\begin{array}{l}\text { Risk of } \\
\text { collapse }\end{array}$ & 0.348 & 0.104 & 3 & 0.342 & 0.342 & 0.317 \\
\hline Avg. & & & & & & & 0.410 & 0.314 & 0.276 \\
\hline Rank & & & & & & & 1 & 2 & 3 \\
\hline
\end{tabular}




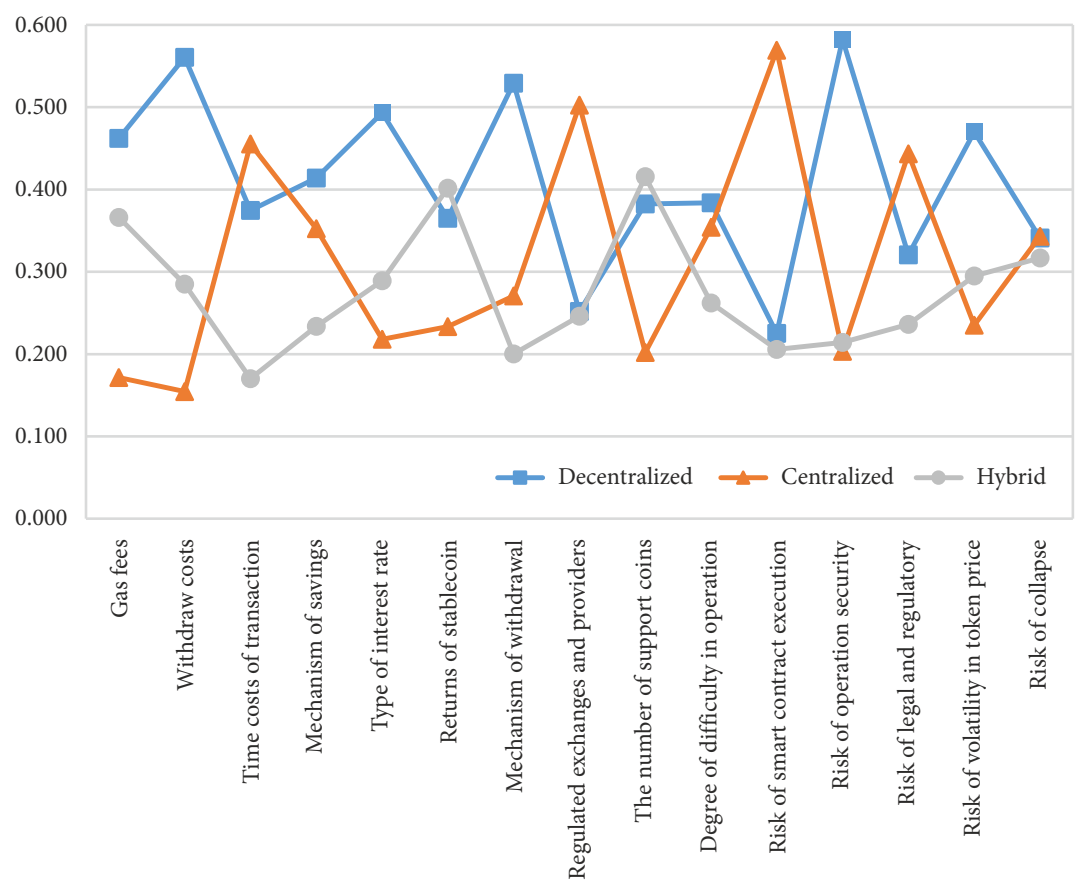

Figure 3. The factors performance of three platforms

Step 3. Normalizing the $D$ matrix

In the light of the established $D$ matrix in Table 10. Then, the decision matrix of $\mathrm{D}$ is normalized and the weighted normalized matrix is created adopting formulas (6) and (7). Table 11 summarizes the normalized results.

Table 11. Normalized the $D$ matrix

\begin{tabular}{|l|c|c|c|c|c|c|c|c|c|c|c|c|c|c|c|}
\hline & GF & WC & TCT & MS & TIR & ROS & MW & REP & TNSC & DDO & RSCE & ROS & RLR & RVTP & ROC \\
\hline DEC & 0.046 & 0.021 & 0.029 & 0.021 & 0.116 & 0.042 & 0.013 & 0.003 & 0.009 & 0.011 & 0.011 & 0.035 & 0.014 & 0.019 & 0.035 \\
\hline CEN & 0.017 & 0.006 & 0.036 & 0.018 & 0.051 & 0.027 & 0.006 & 0.007 & 0.005 & 0.010 & 0.028 & 0.012 & 0.020 & 0.009 & 0.036 \\
\hline HYB & 0.036 & 0.010 & 0.013 & 0.012 & 0.068 & 0.046 & 0.005 & 0.003 & 0.009 & 0.007 & 0.010 & 0.013 & 0.010 & 0.012 & 0.033 \\
\hline
\end{tabular}

Note: Decentralized (DEC), Centralized (CEN), Hybrid (HYB), Gas fee (GF), Withdraw costs (WC), Time costs transaction (TCT), Mechanism of savings (MS), Type of Interest rate (TIR), Returns of stablecoin (ROS), Mechanism of withdrawal (MW), Regulated exchanges and providers (REP), The number of support coins (TNSC), Degree of difficulty in operation (DDO), Risk of smart contract execution (RSCE), Risk of operational security (ROS), Risk of legal and regulatory (RLR), Risk of volatility in token price (RVTP), Risk of collapse (ROC).

Step 4. Determining the TOPSIS $C_{i}^{*}$

In first place, utilizing the formulas (11) and (12) to obtain the ideal solution and negative ideal solution. Table 12 represents the $S_{i}^{*}$ and $S_{i}^{-}$. In second place, the relative closeness to the ideal solution of each decision unit, $C_{i}^{*}$ is computed employing Eq. (13) and the performance of external financing approach is ranked (see Table 13). 
Table 12. Resultant of $S_{i}^{*}$ and $S_{i}^{-}$

\begin{tabular}{|c|c|c|}
\hline & $S_{i}^{*}$ & $S_{i}^{-}$ \\
\hline DEC & 0.019 & 0.081 \\
\hline CEN & 0.079 & 0.031 \\
\hline HYB & 0.064 & 0.033 \\
\hline
\end{tabular}

Table 13. Summary of the TOPSIS $C_{i}^{*}$

\begin{tabular}{|c|c|c|}
\hline & $C_{i}^{*}$ & Rank \\
\hline DEC & 0.804 & 1 \\
\hline CEN & 0.283 & 3 \\
\hline HYB & 0.338 & 2 \\
\hline
\end{tabular}

Step 5. Ranking the optimal token exchanges platform

With the results of ranking by the TOPSIS which the sequential is Decentralized (0.804)> Hybrid (0.338) > Centralized (0.283) (see Table 13). Decentralized exchanges platform has been found to be the optimal alternative for investors or corporations in Taiwan. The $C_{i}^{*}$ of three platforms is Decentralized (0.804), Centralized (0.283), and Hybrid (0.338), which represents that Decentralized is the abovementioned optimal platform. This means when investors or corporations in Taiwan want to implement the token for obtaining returns, they should focus on the Decentralized exchanges platform.

\section{Conclusions}

The corporations and investors are investing in cryptocurrencies increasingly. Due to its low transaction fees, merchants are able to lower their costs and raise their profitability. Nevertheless, the exchange platform of token includes 3 types such as Decentralized, Centralized and Hybrid, the advantages and disadvantages are different for corporations and investors in these platforms. Generally, corporations and investors in Taiwan are confuse on determination of the optimal alternative field through the MCDM process, hence the determination of optimal crypto exchange platform is a complex problem for corporations and investors. The results of this research indicate that the optimal token exchange platform is "Decentralized", which means if corporations or investors in Taiwan would like to implement the crypto into their portfolio, it should focus on the "Decentralized exchange platform". Moreover, the critical factors are "TIR", "ROS", and "ROC". That represents the interest rates, returns, and collapse of exchange platform are concern by investors in token fields. So far, the returns of Decentralized platform are higher than others. But, high returns imply high risks. Therefore, investors have to concern about the risks of Decentralized platform cautiously when they implement the token plan.

The proposed model that integration of the Delphi method, BWM and TOPSIS algorithm to determine the suitable token exchange platforms at Taiwan. The application of this combination model consists of the formation of the quartile deviation that collects and constructs the research model, then calculation of the relative weights via BWM for each factor and platform, determining the ranking of optimal platform by TOPSIS. This model and the corresponding research results can provide academic and commerce support to the corporations or investors in Taiwan. In academic, the combination of decision-making model which can provide investors or corporations with valuable guidance for evaluating the optimal token exchange platform to investors in Taiwan. In commercial, this integration model which may provide corporations or investors with a useful tool to measure the suitable token exchange platform in Taiwan. 
The limitations of this study include 2 perspectives are as below:

1. Because we are trying to reduce the number of complex evaluation steps in this study, we recognize the limitations of applying BWM and TOPSIS cause the model have not considered the ambiguous nature of humans. Future studies can implement the fuzzy theories in this field.

2. The developed model and application of this study is based on science of expert decision making, extending the survey to more investors will future improve the scope and application of this study.

\section{Conflicts of interest}

The authors have no conflicts of interest to report.

\section{References}

Achu, A. L., Thomas, J., \& Reghunath, R. (2020). Multi-criteria decision analysis for delineation of groundwater potential zones in a tropical river basin using remote sensing, GIS and analytical hierarchy process (AHP). Groundwater for Sustainable Development, 10, 100365. https://doi.org/10.1016/j.gsd.2020.100365

Ahluwalia, S., Mahto, R. V., \& Guerrero, M. (2020). Blockchain technology and startup financing: A transaction cost economics perspective. Technological Forecasting and Social Change, 151, 119854. https://doi.org/10.1016/j.techfore.2019.119854

Alexander, C., Choi, J., Massie, H. R., \& Sohn, S. (2020). Price discovery and microstructure in ether spot and derivative markets. International Review of Financial Analysis, 71, 101506. https://doi.org/10.1016/j.irfa.2020.101506

Ali-Yrkko, J., Rouvinen, P., Seppala, T., \& Yla-Anttila, P. (2011). Who captures value in global supply chains? Case Nokia N95 Smartphone. Journal of Industry, Competition and Trade, 11(3), 263-278. https://doi.org/10.1007/s10842-011-0107-4

Andrada-Félix, J., Fernandez-Perez, A., \& Sosvilla-Rivero, S. (2020). Distant or close cousins: Connectedness between cryptocurrencies and traditional currencies volatilities. Journal of International Financial Markets, Institutions and Money, 67, 101219. https://doi.org/10.1016/j.intfin.2020.101219

Arslanian, H., \& Fischer, F. (2019). The crypto-asset ecosystem. In The future of finance (pp. 157-163). Palgrave Macmillan, Cham. https://doi.org/10.1007/978-3-030-14533-0_13

Aziz, A. T. I. F. (2019). Cryptocurrency: Evolution \& legal dimension. International Journal of Business, Economics and Law, 18(4), 31-33.

Baidya, R., Dey, P. K., Ghosh, S. K., \& Petridis, K. (2018). Strategic maintenance technique selection using combined quality function deployment, the analytic hierarchy process and the benefit of doubt approach. The International Journal of Advanced Manufacturing Technology, 94(1-4), 31-44. https://doi.org/10.1007/s00170-016-9540-1

Bentov, I., Ji, Y., Zhang, F., Breidenbach, L., Daian, P., \& Juels, A. (2019, November). Tesseract: Realtime cryptocurrency exchange using trusted hardware. In Proceedings of the 2019 ACM SIGSAC Conference on Computer and Communications Security (pp. 1521-1538). https://doi.org/10.1145/3319535.3363221

Bouri, E., Lau, C. K. M., Lucey, B., \& Roubaud, D. (2019). Trading volume and the predictability of return and volatility in the cryptocurrency market. Finance Research Letters, 29, 340-346.

https://doi.org/10.1016/j.frl.2018.08.015 
Brauneis, A., \& Mestel, R. (2019). Cryptocurrency-portfolios in a mean-variance framework. Finance Research Letters, 28, 259-264. https://doi.org/10.1016/j.frl.2018.05.008

Bunjaku, F., Gorgieva-Trajkovska, O., \& Miteva-Kacarski, E. (2017). Cryptocurrencies - advantages and disadvantages. Journal of Economics, 2(1), 31-39.

Chen, Y., \& Bellavitis, C. (2020). Blockchain disruption and decentralized finance: The rise of decentralized business models. Journal of Business Venturing Insights, 13, e00151. https://doi.org/10.1016/j.jbvi.2019.e00151

Chuen, D. L. K., Guo, L., \& Wang, Y. (2018). Cryptocurrency: A new investment opportunity? The Journal of Alternative Investments, 20(3), 16-40. https://doi.org/10.3905/jai.2018.20.3.016

Coin Market Cap. (2020). Cryptocurrencies by market capitalization. Retrieved August 25, 2020, from https://coinmarketcap.com/

CoinGecko. (2020a). NEXO market capitals. Retrieved July 09, 2020, from https://www.coingecko.com/ en/coins/nexo\#markets

CoinGecko. (2020b). Celsius network market capitals. Retrieved July 09, 2020, from https://www.coingecko.com/en/coins/celsius-network-token

Conrad, C., Custovic, A., \& Ghysels, E. (2018). Long-and short-term cryptocurrency volatility components: A GARCH-MIDAS analysis. Journal of Risk and Financial Management, 11(2), 23. https://doi.org/10.3390/jrfm11020023

Corbet, S., Larkin, C., Lucey, B., Meegan, A., \& Yarovaya, L. (2020). Cryptocurrency reaction to FOMC Announcements: Evidence of heterogeneity based on blockchain stack position. Journal of Financial Stability, 46, 100706. https://doi.org/10.1016/j.jfs.2019.100706

DeFi Market Cap. (2020). Top 100 Defi Tokens by market capitalization. Retrieved January 09, 2010, from https://defimarketcap.io/

Easley, D., O'Hara, M., \& Basu, S. (2019). From mining to markets: The evolution of bitcoin transaction fees. Journal of Financial Economics, 134(1), 91-109. https://doi.org/10.1016/j.jfineco.2019.03.004

Enoksen, F. A., Landsnes, C. J., Lučivjanská, K., \& Molnár, P. (2020). Understanding risk of bubbles in cryptocurrencies. Journal of Economic Behavior \& Organization, 176, 129-144. https://doi.org/10.1016/j.jebo.2020.05.005

Ghosh, A., Gupta, S., Dua, A., \& Kumar, N. (2020). Security of Cryptocurrencies in blockchain technology: State-of-art, challenges and future prospects. Journal of Network and Computer Applications, 163, 102635. https://doi.org/10.1016/j.jnca.2020.102635

Hamdan, S., \& Cheaitou, A. (2017). Supplier selection and order allocation with green criteria: An MCDM and multi-objective optimization approach. Computers \& Operations Research, 81, 282-304. https://doi.org/10.1016/j.cor.2016.11.005

Hasson, F., \& Keeney, S. (2011). Enhancing rigour in the Delphi technique research. Technological Forecasting and Social Change, 78(9), 1695-1704. https://doi.org/10.1016/j.techfore.2011.04.005

Ho, W., \& Ma, X. (2018). The state-of-the-art integrations and applications of the analytic hierarchy process. European Journal of Operational Research, 267(2), 399-414. https://doi.org/10.1016/j.ejor.2017.09.007

Hwang, C., \& Yoon, K. (1981). Multiple attribute decision making: Methods and application. Springer Publications. https://doi.org/10.1007/978-3-642-48318-9

Issaoui, Y., Khiat, A., Bahnasse, A., \& Ouajji, H. (2019). Smart logistics: Study of the application of blockchain technology. Procedia Computer Science, 160, 266-271. https://doi.org/10.1016/j.procs.2019.09.467

Ivaniuk, V. (2020). Cryptocurrency exchange regulation - An international review. Studia Prawnoustrojowe, 48, 67-77. 
Kamaruzzaman, S. N., Lou, E. C. W., Wong, P. F., Wood, R., \& Che-Ani, A. I. (2018). Developing weighting system for refurbishment building assessment scheme in Malaysia through analytic hierarchy process (AHP) approach. Energy Policy, 112, 280-290. https://doi.org/10.1016/j.enpol.2017.10.023

Kheybari, S., Kazemi, M., \& Rezaei, J. (2019). Bioethanol facility location selection using best-worst method. Applied energy, 242, 612-623. https://doi.org/10.1016/j.apenergy.2019.03.054

Kilic, B., \& Ucler, C. (2019). Stress among ab-initio pilots: A model of contributing factors by AHP. Journal of Air Transport Management, 80, 101706. https://doi.org/10.1016/j.jairtraman.2019.101706

Kimani, D., Adams, K., Attah-Boakye, R., Ullah, S., Frecknall-Hughes, J., \& Kim, J. (2020). Blockchain, business and the fourth industrial revolution: Whence, whither, wherefore and how? Technological Forecasting and Social Change, 161, 120254. https://doi.org/10.1016/j.techfore.2020.120254

Kumar, G., Saha, R., Buchanan, W. J., Geetha, G., Thomas, R., Rai, M. K., Kim, T.-H. \& Alazab, M. (2020). Decentralized accessibility of e-commerce products through blockchain technology. Sustainable Cities and Society, 62, 102361. https://doi.org/10.1016/j.scs.2020.102361

Libra Association. (2019). Libra White Paper. Retrieved August 26, 2020, from https://libra.org/en-US/ white-paper/

Lin, C. Y. (2020). Optimal core operation in supply chain finance ecosystem by integrating the fuzzy algorithm and hierarchical framework. International Journal of Computational Intelligence Systems, 13(1), 259-274. https://doi.org/10.2991/ijcis.d.200226.001

Lin, S. W. (2017). Identifying the critical success factors and an optimal solution for mobile technology adoption in travel agencies. International Journal of Tourism Research, 19(2), 127-144. https://doi.org/10.1002/jtr.2092

Lee, J. Y. (2019). A decentralized token economy: How blockchain and cryptocurrency can revolutionize business. Business Horizons, 62(6), 773-784. https://doi.org/10.1016/j.bushor.2019.08.003

Lee, S., Kim, B. S., Kim, Y., Kim, W., \& Ahn, W. (2018). The framework for factors affecting technology transfer for suppliers and buyers of technology in Korea. Technology Analysis \& Strategic Management, 30(2), 172-185. https://doi.org/10.1080/09537325.2017.1297787

Liang, F., Brunelli, M., \& Rezaei, J. (2020). Consistency issues in the best worst method: Measurements and thresholds. Omega, 96, 102175. https://doi.org/10.1016/j.omega.2019.102175

Linden, G., Kraemer, K. L., \& Dedrick, J. (2009). Who captures value in a global innovation network? The case of Apple's iPod. Communications of the ACM, 52(3), 140-144. https://doi.org/10.1145/1467247.1467280

Liu, W., Semeyutin, A., Lau, C. K. M., \& Gozgor, G. (2020). Forecasting Value-at-Risk of Cryptocurrencies with RiskMetrics type models. Research in International Business and Finance, 54, 101259. https://doi.org/10.1016/j.ribaf.2020.101259

Luo, X. (2019). Application and evaluation of payment channel in hybrid decentralized Ethereum token exchange [Doctoral dissertation]. University of British Columbia.

Luo, X., Cai, W., Wang, Z., Li, X., \& Leung, C. V. (2019, May). A payment channel based hybrid decentralized ethereum token exchange. In 2019 IEEE International Conference on Blockchain and Cryptocurrency (ICBC) (pp. 48-49). IEEE. https://doi.org/10.1109/BLOC.2019.8751454

Ma, F., Liang, C., Ma, Y., \& Wahab, M. I. M. (2020). Cryptocurrency volatility forecasting: A Markov regime-switching MIDAS approach. Journal of Forecasting, 39(8), 1277-1290. https://doi.org/10.1002/for.2691

Malek, J., \& Desai, T. N. (2019). Prioritization of sustainable manufacturing barriers using Best Worst Method. Journal of Cleaner Production, 226, 589-600. https://doi.org/10.1016/j.jclepro.2019.04.056

Martino, P., Wang, K. J., Bellavitis, C., \& DaSilva, C. M. (2019). An introduction to blockchain, cryptocurrency and initial coin offerings. In New frontiers in entrepreneurial finance research (pp. 181206). World Scientific Publishing. https://doi.org/10.1142/9789811202766_0007 
Matkovskyy, R. (2019). Centralized and decentralized bitcoin markets: Euro vs USD vs GBP. The Quarterly Review of Economics and Finance, 71, 270-279. https://doi.org/10.1016/j.qref.2018.09.005

Moin, A., Sirer, E. G., \& Sekniqi, K. (2019). A classification framework for stablecoin designs. arXiv preprint arXiv: 1910.10098

Nabilou, H. (2019). How to regulate bitcoin? Decentralized regulation for a decentralized cryptocurrency. International Journal of Law and Information Technology, 27(3), 266-291. https://doi.org/10.1093/ijlit/eaz008

Nizamuddin, N., Salah, K., Azad, M. A., Arshad, J., \& Rehman, M. H. (2019). Decentralized document version control using ethereum blockchain and IPFS. Computers \& Electrical Engineering, 76, 183-197. https://doi.org/10.1016/j.compeleceng.2019.03.014

Nourmohamadi Shalke, P., Paydar, M. M., \& Hajiaghaei-Keshteli, M. (2018). Sustainable supplier selection and order allocation through quantity discounts. International Journal of Management Science and Engineering Management, 13(1), 20-32. https://doi.org/10.1080/17509653.2016.1269246

Omrani, H., Amini, M., \& Alizadeh, A. (2020). An integrated group best-worst method - Data envelopment analysis approach for evaluating road safety: A case of Iran. Measurement, 152, 107330. https://doi.org/10.1016/j.measurement.2019.107330

Pamučar, D., Ecer, F., Cirovic, G., \& Arlasheedi, M. A. (2020). Application of improved Best Worst Method (BWM) in Real-World Problems. Mathematics, 8(8), 1342. https://doi.org/10.3390/math8081342

Patel, M. M., Tanwar, S., Gupta, R., \& Kumar, N. (2020). A deep learning-based cryptocurrency price prediction scheme for financial institutions. Journal of Information Security and Applications, 55, 102583. https://doi.org/10.1016/j.jisa.2020.102583

Pereira, J., Tavalaei, M. M., \& Ozalp, H. (2019). Blockchain-based platforms: Decentralized infrastructures and its boundary conditions. Technological Forecasting and Social Change, 146, 94-102. https://doi.org/10.1016/j.techfore.2019.04.030

Peters, G. W., Chapelle, A., \& Panayi, E. (2016). Opening discussion on banking sector risk exposures and vulnerabilities from Virtual currencies: An Operational Risk perspective. Journal of Banking Regulation, 17(4), 239-272. https://doi.org/10.1057/jbr.2015.10

Poongodi, M., Sharma, A., Vijayakumar, V., Bhardwaj, V., Sharma, A. P., Iqbal, R., \& Kumar, R. (2020). Prediction of the price of Ethereum blockchain cryptocurrency in an industrial finance system. Computers \& Electrical Engineering, 81, 106527. https://doi.org/10.1016/j.compeleceng.2019.106527

Rehman, M. H. u., Salah, K., Damiani, E., \& Svetinovic, D. (2019). Trust in blockchain cryptocurrency ecosystem. IEEE Transactions on Engineering Management, 67(4), 1196-1212. https://doi.org/10.1109/TEM.2019.2948861

Rezaei, J. (2015). Best-worst multi-criteria decision-making method. Omega, 53, 49-57. https://doi.org/10.1016/j.omega.2014.11.009

Rezaei, J. (2016). Best-worst multi-criteria decision-making method: Some properties and a linear model. Omega, 64, 126-130. https://doi.org/10.1016/j.omega.2015.12.001

Rezaei, J., van Roekel, W. S., \& Tavasszy, L. (2018). Measuring the relative importance of the logistics performance index indicators using Best Worst Method. Transport Policy, 68, 158-169. https://doi.org/10.1016/j.tranpol.2018.05.007

Ricci, S., Ferreira, E., Menasche, D. S., Ziviani, A., Souza, J. E., \& Vieira, A. B. (2018). Learning blockchain delays: A queueing theory approach. ACM SIGMETRICS Performance Evaluation Review, 46(3), 122-125. https://doi.org/10.1145/3308897.3308952

Roberti, F., Oberegger, U. F., Lucchi, E., \& Troi, A. (2017). Energy retrofit and conservation of a historic building using multi-objective optimization and an analytic hierarchy process. Energy and Buildings, 138, 1-10. https://doi.org/10.1016/j.enbuild.2016.12.028 
Schär, F. (2020). Decentralized finance: On blockchain- and smart contract-based financial markets. https://doi.org/10.2139/ssrn.3571335

Shapiro, D. C. (2018). Taxation and regulation in decentralized exchanges. Journal of Taxation of Investments, 36(1), 3-13.

Silfversten, E., Favaro, M., Slapakova, L., Ishikawa, S., Liu, J., \& Salas, A. (2020). Exploring the use of Zcash cryptocurrency for illicit or criminal purposes. Retrieved August 13, 2020, from https://www. rand.org/content/dam/rand/pubs/research_reports/RR4400/RR4418/RAND_RR4418.pdf

Singh, A., Click, K., Parizi, R. M., Zhang, Q., Dehghantanha, A., \& Choo, K. K. R. (2020). Sidechain technologies in blockchain networks: An examination and state-of-the-art review. Journal of Network and Computer Applications, 149, 102471. https://doi.org/10.1016/j.jnca.2019.102471

Söylemez, Y. (2019). Cryptocurrency derivatives: The case of Bitcoin. In U. Hacioglu (Ed.), Blockchain economics and financial market innovation (pp. 515-530). Springer, Cham. https://doi.org/10.1007/978-3-030-25275-5_25

Sung, W. C. (2001). Application of Delphi method, a qualitative and quantitative analysis, to the healthcare management. Journal of Healthcare Management, 2(2), 11-19.

Tapscott, A., \& Tapscott, D. (2017). How blockchain is changing finance. Harvard Business Review, $1(9), 2-5$.

Tian, H., Xue, K., Li, S., Xu, J., Liu, J., \& Zhao, J. (2020). Enabling cross-chain transactions: A decentralized cryptocurrency exchange protocol. arXiv preprint arXiv:2005.03199

van de Kaa, G., Kamp, L., \& Rezaei, J. (2017). Selection of biomass thermochemical conversion technology in the Netherlands: A best worst method approach. Journal of Cleaner Production, 166, 32-39. https://doi.org/10.1016/j.jclepro.2017.07.052

Veisi, H., Liaghati, H., \& Alipour, A. (2016). Developing an ethics-based approach to indicators of sustainable agriculture using analytic hierarchy process (AHP). Ecological Indicators, 60, 644-654. https://doi.org/10.1016/j.ecolind.2015.08.012

Vora, G. (2015). Cryptocurrencies: Are disruptive financial innovations here? Modern Economy, 6(7), 816. https://doi.org/10.4236/me.2015.67077

Walther, T., Klein, T., \& Bouri, E. (2019). Exogenous drivers of Bitcoin and Cryptocurrency volatility - A mixed data sampling approach to forecasting. Journal of International Financial Markets, Institutions and Money, 63, 101133. https://doi.org/10.1016/j.intfin.2019.101133

Wu, C. R., Lin, C. T., \& Chen, H. C. (2007). Evaluating competitive advantage of the location for Taiwanese hospitals. Journal of Information and Optimization Sciences, 28(5), 841-868. https://doi.org/10.1080/02522667.2007.10699777

Xia, P., Wang, H., Zhang, B., Ji, R., Gao, B., Wu, L., Luo, X., \& Xu, G. (2020). Characterizing cryptocurrency exchange scams. Computers \& Security, 98, 101993. https://doi.org/10.1016/j.cose.2020.101993

Xu, Q., Zhang, Y., \& Zhang, Z. (2021). Tail-risk spillovers in cryptocurrency markets. Finance Research Letters, 38, 101453. https://doi.org/10.1016/j.frl.2020.101453

You, P., Guo, S., Zhao, H., \& Zhao, H. (2017). Operation performance evaluation of power grid enterprise using a hybrid BWM-TOPSIS method. Sustainability, 9(12), 2329. https://doi.org/10.3390/su9122329

Zhang, L., Xie, Y., Zheng, Y., Xue, W., Zheng, X., \& Xu, X. (2020). The challenges and countermeasures of blockchain in finance and economics. Systems Research and Behavioral Science, 37(4), 691-698. https://doi.org/10.1002/sres.2710 